\title{
Colourfastness properties of digital printed cotton fabric
}

Spoorti V. Uppinal and Geeta Mahale

Received: 10.11.2017; Revised: 07.04.2018; Accepted: 26.04.2018

See end of the paper for authors' affiliations

Spoorti V. Uppinal

Department of Textile and

Apparel Designing, College of

Rural Home Science, University

of Agricultural Sciences, Dharwad

(Karnataka) India

Email : spoortivu85@gmail.com
ABSTRACT : Colourfastness is the most significant parameters of the quality of printed fabrics in the textile industry. The aim of this study was to assess the colourfastness properties of digital printed cotton fabric. In order to accomplish this experiment, commercially available pre-treated cotton fabric was digital printed with selected five different colours (black, blue, green, red and yellow). All the printed fabrics were treated with superheated steam at $110^{\circ} \mathrm{C}$ for 5 min for colour fixation. Steamed fabric samples were finally washed in $10 \mathrm{~g} / \mathrm{l} \mathrm{non-ionic} \mathrm{detergent}$ (Ahurachem) until all the unreacted dyes and chemicals were removed from the fabric surface. The fastness properties of the printed cotton samples were evaluated and the results revealed that number of washes did affect the colour strength $(\mathrm{K} / \mathrm{S})$ of the printed samples. Irrespective of colours, wet rubbing, sunlight, alkali media perspiration and damp sublimastation attained greater percentage of colour strength loss than control samples.

KEY WORDS: Colour strength, Digital printing, Fastness, Pre-treatment, Post-treatment

- HOW TO CITE THIS PAPER : Uppinal, Spoorti V. and Mahale, Geeta (2018). Colourfastness properties of digital printed cotton fabric. Asian J. Home Sci., 13 (1) : 237-240, DOI: 10.15740/HAS/AJHS/13.1/237240. Copyright@ 2018: Hind Agri-Horticultural Society. 